\title{
A Comparative Study of Ion Diffusion from Calcium Hydroxide with Various Herbal Pastes through Dentin
}

\author{
${ }^{1}$ Priyanka Dausage, ${ }^{2}$ Rajesh B Dhirawani, ${ }^{3}$ Jayant Marya, ${ }^{4}$ Vrinda Dhirawani, ${ }^{5}$ Vijayendra Kumar
}

\begin{abstract}
Aim: The aim of this study was to evaluate the diffusion ability of ions through dentinal tubules of different nonalcoholic calcium hydroxide-containing herbal pastes and compare it with the calcium hydroxide paste prepared with saline.

Materials and methods: A total of 36 single-rooted premolar teeth were used in this study. The tooth crowns were removed and the root canals were prepared. Depending on the vehicle to be used for preparing calcium hydroxide pastes, six groups were made: Group I: $\mathrm{Ca}(\mathrm{OH})_{2}$ saline paste (control group), group II: $\mathrm{Ca}(\mathrm{OH})_{2}$ papaya latex paste, group III: $\mathrm{Ca}(\mathrm{OH})_{2}$ coconut water paste, group IV: $\mathrm{Ca}(\mathrm{OH})_{2}$ Ashwagandha (Withania somnifera) paste, group V: $\mathrm{Ca}(\mathrm{OH})_{2}$ Tulsi (Ocimum tenuiflorum) paste, and group VI: $\mathrm{Ca}(\mathrm{OH})_{2}$ garlic (Allium sativum) paste. After biomechanical preparation, calcium hydroxide herbal paste dressings were applied and sealed with resin-based cement. The teeth were placed in containers with deionized water, and the $\mathrm{pH}$ of the water was measured at regular intervals over $3,24,72$, and 168 hours.
\end{abstract}

Results: We observed that all herbal pastes allowed the diffusion of ions, but pastes prepared with Ashwagandha and papaya latex showed more ion diffusion after 168 hours and marked increase in $\mathrm{pH}$, depicting better support for calcium hydroxide action.

Conclusion: We conclude that Ashwagandha and papaya latex allow better diffusion of calcium hydroxide through dentinal tubules, thus enhancing its action, and advise its use as a vehicle for placing intracanal medicament.

Keywords: Calcium hydroxide, Herbal paste, Intracanal medicament, Ion diffusion.

How to cite this article: Dausage P, Dhirawani RB, Marya J, Dhirawani V, Kumar V. A Comparative Study of Ion Diffusion

\footnotetext{
${ }^{1}$ Consultant, ${ }^{2}$ Professor and Head, ${ }^{3,4}$ Postgraduate Student ${ }^{5}$ Reader

${ }^{1}$ Department of Pedodontics and Preventive Dentistry, Jabalpur Hospital \& Research Centre, Jabalpur, Madhya Pradesh, India

${ }^{2,3}$ Department of Oral and Maxillofacial Surgery, Hitkarini Dental College \& Hospital, Jabalpur, Madhya Pradesh, India

${ }^{4}$ Department of Conservative Dentistry, Hitkarini Dental College \& Hospital, Jabalpur, Madhya Pradesh, India

${ }^{5}$ Department of Oral and Maxillofacial Surgery, Malla Reddy Institute of Dental Sciences, Hyderabad, Telangana, India

Corresponding Author: Priyanka Dausage, Consultant Department of Pedodontics and Preventive Dentistry, Jabalpur Hospital \& Research Centre, Jabalpur, Madhya Pradesh, India Phone: +917612665508, e-mail: pdausage@yahoo.co.in
}

from Calcium Hydroxide with Various Herbal Pastes through Dentin. Int J Clin Pediatr Dent 2017;10(1):41-44.

\section{Source of support: Nil \\ Conflict of interest: None}

\section{INTRODUCTION}

Antimicrobial intracanal medicaments are used to complement the disinfection of the root canal system. Calcium hydroxide $\left[\mathrm{Ca}(\mathrm{OH})_{2}\right]$ has been widely used for its biological and antimicrobial ability, to dissolve organic tissues, and the capacity to inactivate bacterial endotoxins. The effectiveness of $\mathrm{Ca}(\mathrm{OH})_{2}$-based pastes depends on diffusion of hydroxyl ions $\left[\mathrm{OH}^{-}\right]$in concentrations to reach adequate $\mathrm{pH}$ levels. ${ }^{1,2}$

The success of calcium hydroxide paste as a root canal dressing is related to its dissociation into calcium and hydroxyl ions. ${ }^{3}$ Hydroxyl ions $\left[\mathrm{OH}^{-}\right]$are highly reactive free radicals that show extreme reactivity with several biomolecules. This reactivity is indiscriminate, so this free radical rarely diffuses away from the sites of generation. The lethal effects of hydroxyl ions in bacterial cells are due to the damage of bacterial cytoplasmic membrane, protein denaturation, and damage to the bacterial deoxyribonucleic acid. ${ }^{4}$

The $\mathrm{Ca}(\mathrm{OH})_{2}$ powder for root canal dressing has been used with different vehicles, such as distilled water, camphorated monochlorophenol, normal saline, cresatin, glycerine, and propylene glycol (PG). The dissociation of $\mathrm{Ca}(\mathrm{OH})_{2}$ into $\mathrm{OH}^{-}$and $\mathrm{Ca}^{2+}$ depends on the vehicle used to prepare the paste, and it should allow gradual and efficient dissociation of hydroxyl ions for better action of calcium hydroxide. ${ }^{5,6}$ Studies have demonstrated that the vehicle can exert a great influence on the release of ions. ${ }^{7}$

Thus, several associations have been investigated to determine the effectiveness of calcium hydroxide pastes. Besides allowing dissociation of the calcium hydroxide, the vehicle also should enhance the antimicrobial capacity of the paste. According to Gomes et $\mathrm{al}^{7}{ }^{7}$ chlorhexidine may be used as a vehicle in an attempt to increase the antimicrobial capacity of calcium hydroxide pastes, as it is effective against Gram-positive and Gram-negative, aerobic and facultative anaerobic microorganisms, yeasts, and viruses. Based on these aspects, this study evaluated 
the ability of calcium hydroxide mixed with different vehicles to diffuse through dentin. ${ }^{8}$

Considering the antimicrobial potential of a herbalcalcium hydroxide association, it becomes important to determine how well such pastes can promote the diffusion of ions through dentinal tubules, an attribute essential to the therapeutic effect of any calcium hydroxide paste.

\section{MATERIALS AND METHODS}

The present study was carried out in the Department of Pedodontics and Preventive Dentistry, Hitkarini Dental College and Hospital, Jabalpur, Madhya Pradesh, India, and was approved by the institutional ethical committee.

The study was done on 36 extracted single-rooted premolar teeth with the following criteria:

\section{Inclusion Criteria}

- Single-rooted premolar teeth

- Teeth with no gross caries or fracture

- Teeth having patent canals

- Teeth with full length of root intact.

\section{Exclusion Criteria}

- Teeth with gross deviation in their normal anatomy

- Teeth with internal resorption and external resorption

- Teeth having fractured roots

- Teeth with obstruction or calcification within the canal system were excluded from this study.

\section{Specimen Preparation ${ }^{3}$}

A total of 36 extracted human single-rooted premolar teeth were collected, stored, and disinfected (10\% formaldehyde) and handled as per the recommendation and guidelines laid down by the Centers for Disease Control . The crowns were transversely sectioned with a carborundum disk (Ukam, USA), at the cementoenamel junction level. Root canal length was measured by inserting a \#15 K-file (Dentsply, Petrópolis, Brazil) with a rubber stop. When the file tip reached the apical foramen, the stop was leveled to the cervical edge of the root, and the canal length was recorded. The working length was established by subtracting $1 \mathrm{~mm}$ from the total root canal length. Apical preparation was performed up to this limit, up to file \#40. The root canals were irrigated with distilled water throughout the instrumentation procedure with a 2-mL disposable syringe. After instrumentation, a \#40 file was inserted to the total working length for apical cleaning, and the root canal was filled with an ethylenediaminetetraacetic acid solution (Healix Medico, Mumbai) for 3 minutes. After this period, the root canals were rinsed with saline solution and dried with absorbent paper points (Dentsply, Petrópolis, Brazil).

\section{Sample Size and Distribution}

The teeth were randomly divided into six groups according to the following calcium hydroxide pastes used as an intracanal medicament:

- Group I $(n=6)$ : Calcium hydroxide-saline paste, prepared by mixing $1 \mathrm{gm}$ of calcium hydroxide with 2 $\mathrm{mL}$ of saline.

- Group II $(n=6)$ : Calcium hydroxide-papaya latex paste, prepared by mixing $1 \mathrm{gm}$ calcium hydroxide with $2 \mathrm{~mL}$ of papaya latex extract.

- Group III $(n=6)$ : Calcium hydroxide-coconut water paste, prepared by mixing $1 \mathrm{gm}$ calcium hydroxide with $2 \mathrm{~mL}$ of coconut water.

- Group IV $(n=6)$ : Calcium hydroxide-Ashwagandha paste, prepared by mixing $1 \mathrm{gm}$ calcium hydroxide with $2 \mathrm{~mL}$ of Ashwagandha extract.

- Group V $(n=6)$ : Calcium hydroxide-Tulsi paste, prepared by mixing $1 \mathrm{gm}$ calcium hydroxide with $2 \mathrm{~mL}$ of Tulsi extract.

- Group VI $(n=6)$ : Calcium hydroxide-garlic paste, prepared by mixing $1 \mathrm{gm}$ calcium hydroxide with $2 \mathrm{~mL}$ of garlic extract.

\section{Preparation of Extracts}

\section{Papaya Latex Extract ${ }^{9}$}

About 10 gm of dried papaya latex was crushed with $100 \mathrm{mM}$ phosphate buffer $(\mathrm{pH}=5.5)$ using acid-washed sand in a pestle mortar in chilly conditions for 10 to $15 \mathrm{~min}$. The mixture was centrifuged at 10,000 rpm for $10 \mathrm{~min}$. The pellet was discarded and the supernatant was kept. To the supernatant, solid ammonium sulfate was added to achieve $45 \%$ saturation at $4^{\circ} \mathrm{C}$. After centrifugation, the pellet was kept and was redissolved in phosphate-buffered saline (1 mL).

\section{Tulsi Leaves, Ashwagandha, Garlic Extract ${ }^{10}$}

About 10 gm of material (dried Tulsi leaves, dried Ashwagandha powder, and chopped garlic cloves) was taken into the thimble of Soxhlet apparatus. The extraction was started using $250 \mathrm{~mL}$ of ethanol. The extraction was continued up to 10 cycles (10 gm of material extracted with $250 \times 10=2.5$ L ethanol). The extract obtained was dried under vacuum and redissolved in $1 \mathrm{~mL}$ saline before use.

\section{Coconut Water}

Coconut water was used as obtained from green coconut and was taken fresh.

Complete filling of the root canals was checked by having the solution overflow through the apical foramen and flow back through the root canal opening. After the complete filling of the root canals, their openings were sealed with temporary cement (Cavit, 3M ESPE ${ }^{\mathrm{TM}}$ ). The 
apical foramen and root canal apex (over the temporary cement) were sealed with epoxy resin (RelyX, 3M ESPETM, India). Next, the teeth were placed in containers with $50 \mathrm{~mL}$ of deionized water $(\mathrm{pH}=6.17)$ and kept in an oven at $37^{\circ} \mathrm{C}$, with $100 \%$ humidity.

After 3, 24,72, and 168 hours, the $\mathrm{pH}$ values of the solutions in the containers were measured using a $\mathrm{pH}$ meter (Digital - 1010 Esico, India), calibrated and standardized with standard buffer solutions (Merck, Germany) at $\mathrm{pH}$ 4.00 and 7.00. Twelve measurements were performed for each group/period. For each measurement, the electrode of the $\mathrm{pH}$ meter was carefully rinsed with deionized water and dried with absorbent paper to eliminate any residues that could interfere with the measurements. The data were recorded in tables, and the differences between groups and periods were statistically analyzed by one-way analysis of variance (ANOVA) and Tukey's post hoc comparisons using Sigma GraphPad Prism ${ }^{\circledR}$ version 6.0.

\section{RESULTS}

In the present study, 36 single-rooted premolar teeth were used and divided into six groups, based on different vehicles used to place calcium hydroxide. At regular intervals of 3,24,72, and 168 hours, the $\mathrm{pH}$ of the water was recorded for each group.

Graph 1 suggests that all the herbal pastes caused the increase in $\mathrm{pH}$ up to 72 hours, and then there is a marked decrease in the $\mathrm{pH}$ with all the herbal preparations. Coconut water was alkaline in nature initially and after 168 hours, the medium was still alkaline. Ashwagandha was the only herbal preparation that increased the $\mathrm{pH}$ up to 168 hours and made the medium alkaline. All the other preparations were acidic at the start of experiment, increased the $\mathrm{pH}$ up to 72 hours, but could not make the medium alkaline. A reduction in $\mathrm{pH}$ after 168 hours was seen with all the extracts.

Table 1 shows the mean $\mathrm{pH}$ values of all groups. Group I was used as a control group, in which saline was mixed with calcium hydroxide, and showed a $\mathrm{pH}$ drift ranging from 6.6 to 6.8 with the mean $\mathrm{pH}$ of 6.6 for 3 hours. No statistically significant difference was observed for the $\mathrm{pH}$ change during 24,72 , and 168 hours $\mathrm{pH}$ measurement ( $\mathrm{p}<0.05)$.

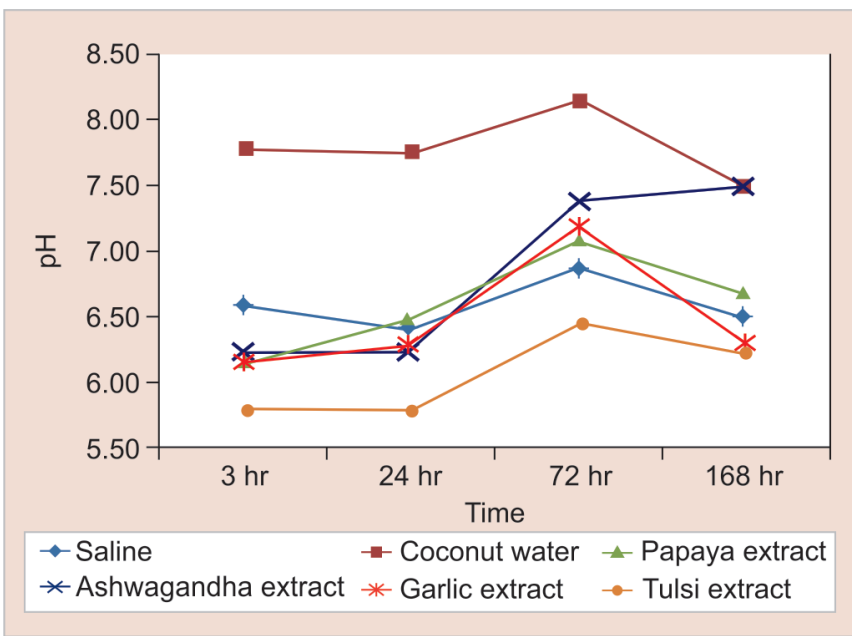

Graph 1: $\mathrm{pH}$ variation over time for the study groups

In group II, papaya latex was used and showed initial mean $\mathrm{pH}$ as 6.14. The $\mathrm{pH}$ was increased with time and was statistically different from that of $\mathrm{pH}$ at 3 hours after 72 hours and 168 hours.

Group III used coconut water mixed with calcium hydroxide and recorded mean $\mathrm{pH}$ of 7.78 , which increased significantly to 8.15 after 72 hours and decreased during 168 hours measurement.

Group IV used Ashwagandha paste and its mean $\mathrm{pH}$ value was increased significantly to 8.08 after 72 hours, as compared with 6.14 after 3 hours. The 168 hours $\mathrm{pH}$ value, though decreased to 7.67 , was still significantly different from the 3 hours $\mathrm{pH}$ value.

Group V was Tulsi paste mixed with calcium hydroxide and showed a significant increase of the mean $\mathrm{pH}$ to 6.45 after 72 hours from initial $\mathrm{pH}$ as 5.8 .

Group VI used garlic paste and showed a significant increase in $\mathrm{pH}$ as 7.2 from initial $\mathrm{pH}$ as 6.15 after 72 hours.

Although all the herbal preparations showed an increase in the $\mathrm{pH}$ of the solution upto 72 hours, only papaya and Ashwagandha paste did not allow the decrease of the $\mathrm{pH}$ after 168 hours, and the mean $\mathrm{pH}$ values were still significantly different from that of the mean $\mathrm{pH}$ at 3 hours thus, inferring that they allow the maximum ionization of calcium hydroxide and promote sustained release of the ions for a longer duration of time.

Table 1: Comparison of mean $\mathrm{pH}$ values between groups at different time intervals

\begin{tabular}{llllll}
\hline Groups & Materials & 3 hours & 24 hours & 72 hours & 168 hours \\
\hline I & $\mathrm{Ca}(\mathrm{OH})_{2}+$ saline & $6.60 \pm 0.44^{\mathrm{a}}$ & $6.30 \pm 0.55^{\mathrm{a}}$ & $6.81 \pm 0.47^{\mathrm{a}}$ & $6.51 \pm 0.37^{\mathrm{a}}$ \\
II & $\mathrm{Ca}(\mathrm{OH})_{2}+$ papaya & $6.14 \pm 0.30^{\mathrm{a}}$ & $6.50 \pm 0.53^{\mathrm{a}}$ & $7.08 \pm 0.58^{\mathrm{b}}$ & $6.67 \pm 0.4^{\mathrm{b}}$ \\
III & $\mathrm{Ca}(\mathrm{OH})_{2}+$ coconut & $7.78 \pm 0.56^{\mathrm{a}}$ & $7.74 \pm 0.41^{\mathrm{a}}$ & $8.15 \pm 0.11^{\mathrm{b}}$ & $7.47 \pm 0.31^{\mathrm{a}}$ \\
IV & $\mathrm{Ca}(\mathrm{OH})_{2}+$ ashwagandha & $6.14 \pm 0.30^{\mathrm{a}}$ & $6.50 \pm 0.53^{\mathrm{a}}$ & $8.08 \pm 0.58^{\mathrm{b}}$ & $7.67 \pm 0.4^{\mathrm{b}}$ \\
V & $\mathrm{Ca}(\mathrm{OH})_{2}+$ tulsi & $5.80 \pm 0.37^{\mathrm{a}}$ & $5.81 \pm 0.25^{\mathrm{a}}$ & $6.45 \pm 0.06^{\mathrm{b}}$ & $6.21 \pm 0.43^{\mathrm{a}}$ \\
VI & $\mathrm{Ca}(\mathrm{OH})_{2}+$ garlic & $6.15 \pm 0.11^{\mathrm{a}}$ & $6.28 \pm 0.15^{\mathrm{a}}$ & $7.20 \pm 0.17^{\mathrm{b}}$ & $6.28 \pm 0.12^{\mathrm{a}}$ \\
\hline
\end{tabular}

Different letters in superscript shows the statistically different values after one-way ANOVA $(p<0.05)$ 


\section{DISCUSSION}

Calcium hydroxide is one of the main root canal dressings used in endodontics. The success of calcium hydroxide as a root canal dressing lies in its dissociation into ionic forms, i.e., calcium and hydroxyl ions. These hydroxyl ions alkalinize the environment and thus help in activating the alkaline phosphatase enzyme, which induces mineralized tissue formation and thus is helpful in the repair process. ${ }^{4}$

To be effective, the hydroxyl ions should be able to diffuse in dentin and remain in pulp tissues at a sufficient concentration to produce the $\mathrm{pH}$ level required to destruct bacteria inside the root canal and dentinal tubules. The action of these ions on tissues and bacteria explains the biological and antimicrobial properties of calcium hydroxide. ${ }^{11}$

Calcium hydroxide is used as paste, and the vehicle required to make the paste of calcium hydroxide may well increase the suitability of calcium hydroxide as a filling. ${ }^{12}$ The studies have proved that aqueous and viscous vehicles have more effectiveness as compared with the oily vehicles. ${ }^{2}$ Similarly, it has been shown that nonalcoholic preparations of PG and bee propolis as vehicles showed good diffusion through dentin. ${ }^{3}$

The present study was aimed to identify some more preparations to be used as a vehicle for calcium hydroxide paste to improve the diffusion capabilities of calcium hydroxide. Aqueous vehicles were used in the present study, which was in accordance with the studies conducted previously. ${ }^{11}$ Herbal preparations are always welcome in present-day science due to the multitude of benefits due to the phytochemicals present in herbs. Withaferin A and 3-b-hydroxy-2,3-dihydro-withanolide $\mathrm{F}$ isolated from Ashwagandha (Withania somnifera) show promising antibacterial, antitumor, immunomodulating, and anti-inflammatory properties. ${ }^{13}$ Such herbal preparations, if used smartly, can provide additional benefits. In the present study, Ashwagandha and the papaya latex showed the diffusion of ions through the dentinal tubules in a sustained manner (up to 168 hours) in comparison with normal saline. All the herbal pastes in the present study, which diffused through the dentinal tubules, presented a better ability to alkalize external root surface after 72 hours when compared with saline.

Coconut water has a much better composition of minerals like calcium, iron, manganese, magnesium, and zinc compared with other fruits. ${ }^{14}$ The better diffusion ability and marked antimicrobial activity make them the best materials, which can be used as vehicles. The use of papaya latex extract and Ashwagandha with calcium hydroxide as an intracanal medicament may thus be suggested.

\section{CONCLUSION}

Ashwagandha and papaya latex extracts as vehicles for calcium hydroxide are suggested as an intracanal medicament. Further studies are required to confirm the present data.

\section{REFERENCES}

1. Pacios MG, de la Casa ML, de Bulacio MI, López ME. Influence of different vehicles on the $\mathrm{pH}$ of calcium hydroxide pastes. J Oral Sci 2004 Jun;46(2):107-111.

2. Lage Marques JLS, Conti R, Antoniazzi JH, Guth I. Avaliação da velocidade de dissociação iônica do hidróxido de cálcio associado a diferentes veículos/In vitro assessment of the ionic dissociation velocity of calcium hydroxide associated to different vehicles. Rev odontol Univ São Paulo 1994 AprJun;8(2):81-87.

3. Montero JC, Mori GG. Assessment of ion diffusion from a calcium hydroxide-propolis paste through dentin. Braz Oral Res (São Paulo) 2012 Jul-Aug;26(4):318-322.

4. Mohammadi Z, Dummer PMH. Properties and applications of calcium hydroxide inendodontics and dental traumatology. Int Endod J 2011 Aug;44(8):697-730.

5. Lima RK, Guerreiro-Tanomaru JM, Faria- Júnior NB, Tanomaru-Filho M. Effectiveness of calcium hydroxide-based intracanal medicaments against Enterococcus faecalis. Int Endod J 2012 Apr;45(4):311-316.

6. Estrela C, Holland R. Calcium hydroxide: study based on scientific evidences. J Appl Oral Sci 2003 Dec;11(4):269-282.

7. Gomes BPFA, Souza SFC, Ferraz CCR, Teixeira FB, Zaia AA, Valdrighi L, Souza-Filho FJ. Effectiveness of 2\% chlorhexidine gel and calcium hydroxide against Enterococcus faecalis in bovine root dentine in vitro. Int Endod J 2003 Apr;36(4): 267-275.

8. Baldev S, Baines S, Brocklehurst K. A necessary modification to the preparation of papain from any high-quality latex of Carica papaya and evidence for the structural integrity of the enzyme produced by traditional methods. Biochem J 1979 Feb;177(2):541-548.

9. Azian MN, Ilia Anisa AN, Iwai Y. Mechanisms of ginger bioactive compounds extract using Soxhlet and accelerated water extraction. World Acad Sci Eng Technol 2014 Jan;8(5): 438-442.

10. Maniglia-Ferreira C, Gomes FDA, Guimarães NLSDL, Vitoriano MDM, Ximenes TA. In vitro analysis of the $\mathrm{pH}$ alteration of the dentine after using different calcium hydroxide-based pastes. RSBO (Online) 2013 Apr-Jun;10(2):122-127.

11. Mori GG, Ferreira FC, Batista FRDS, Godoy AMDS, Nunes DC. Evaluation of the diffusion capacity of calcium hydroxide pastes through the dentinal tubules. Braz Oral Res 2009 AprJun;23(2):113-118.

12. Zmener $\mathrm{O}$, Pameijer $\mathrm{CH}$, Banegas $\mathrm{G}$. An in vitro study of the $\mathrm{pH}$ of three calcium hydroxide dressing materials. Dent Traumatol 2007 Feb;23(1):21-25.

13. Vigliar R, Sdepanian VL, Fagundes-Neto U. Biochemical profile of coconut water from coconut palms planted in an inland region. J Pediatr (Rio J) 2006 Jul-Aug;82(4):308-312.

14. Owais M, Sharad KS, Shehbaz A, Saleemuddin M. Antibacterial efficacy of Withania somnifera (ashwagandha) an indigenous medicinal plant against experimental murine salmonellosis. Phytomedicine 2005 Mar;12(3):229-235. 